\title{
2-Bromo-5-hydroxyphenylporphyrins for photodynamic therapy: Photosensitization efficiency, subcellular localization and in vivo studies
}

\author{
Mafalda Laranjo MSc ${ }^{a, b, *}$, Arménio C. Serrac ${ }^{c}$ Margarida Abrantes ${ }^{a, b}$, \\ Marta Piñeiro ${ }^{c}$, Ana C. Gonçalves ${ }^{b, d}$, João Casalta-Lopes a , Lina Carvalhob,e, \\ Ana B. Sarmento-Ribeiro ${ }^{b, d}$, António Rocha-Gonsalves ${ }^{b, c}$, \\ Filomena Botelho a,b
}

\footnotetext{
a Biophysics Unit - IBILI, Faculty of Medicine, University of Coimbra, Azinhaga de Santa Comba, Celas, 3000-548 Coimbra, Portugal

b CIMAGO, Faculty of Medicine, University of Coimbra, Azinhaga de Santa Comba, Celas, 3000-548 Coimbra, Portugal

c Chymiotechnon - Department of Chemistry, University of Coimbra, Rua Larga, 3000 Coimbra, Portugal

d Applied Molecular Biology Unit, Faculty of Medicine, University of Coimbra, Azinhaga de Santa Comba, Celas, 3000-548

Coimbra, Portugal

e Department of Pathology, Faculty of Medicine, University of Coimbra, Rua Larga, 3000 Coimbra, Portugal

Available online 19 June 2012
}

\section{KEYWORDS}

Photochemotherapy;

Reactive oxygen

species;

Porphyrins;

Colorectal

adenocarcinoma;

Melanoma

\begin{abstract}
Summary
Background: Photodynamic therapy (PDT) is a therapeutic modality capable of inducing cell death by oxidative stress through activation of a sensitizer by light. Aryl-porphyrin with hydroxyl groups are good photosensitizers and presence of bromine atoms can enhance the photodynamic activity through heavy atom effect. These facts and our previous work made pertinent to compare the photodynamic capacity of tetraaryl brominated porphyrin $(\mathrm{TBr} 4)$ with the corresponding diaryl $(\mathrm{BBr} 2)$ derivative.

Methods: Cell cultures were incubated with the sensitizers, ranging from $50 \mathrm{nM}$ to $10 \mu \mathrm{M}$ and irradiated until $10 \mathrm{~J}$. Cell proliferation was analysed by MTT assay. Flow cytometry studies evaluated cell death pathways, mitochondrial membrane potential and ROS. For in vivo studies $\mathrm{Balb} / \mathrm{c}$ nu/nu mice were injected with $4 \times 10^{6}$ cells. After PDT, monitoring was carried out for 12 days to establish Kaplan-Meier survival curves. Tumours were excised and histological analysis was performed.

Results: Both sensitizers seem to accumulate in the mitochondria. The molecules have no intrinsic cytotoxicity or in non-tumour cells at therapeutic concentrations. Both sensitizers induced a significant decrease of cell proliferation and growth of xenografts of melanoma and colorectal
\end{abstract}

\footnotetext{
* Corresponding author at: Biophysics Unit - IBILI, Azinhaga de Santa Comba, Celas, 3000-548 Coimbra, Portugal. Tel.: +351 239 480240 ; fax: +351239480258.

E-mail address: mafaldalaranjo@fmed.uc.pt (M. Laranjo).
} 
adenocarcinoma. Diaryl $\mathrm{BBr} 2$ is more efficient than tetraaryl $\mathrm{TBr} 4$, concerning intracellular ROS production, mitochondrial disruption and induction of cell death. The main cell death pathway is necrosis.

Conclusions: $\mathrm{TBr} 2$ and $\mathrm{BBr} 4$ are promising sensitizers with good photodynamic properties and have the ability to induce cell death in human melanoma and colorectal adenocarcinoma in vitro and in vivo. We consider that $\mathrm{BBr} 2$ is a molecule that should be the subject of extensive studies towards clinical use.

(c) 2012 Elsevier B.V. All rights reserved.

\section{Introduction}

Photodynamic therapy (PDT) has emerged as a promising treatment against cancer [1-3]. It is based on the administration of a non-toxic photosensitizer followed by illumination of the cancer lesion with light of appropriate wavelength [4]. As a result, the excited molecule transfers energy to oxygen, generating singlet oxygen or, otherwise, producing several reactive oxygen species (ROS). The effect is that all these molecules can cause intracellular damages that lead to cell death [5-7]. The success of the PDT is highly dependent on the photophysical and photochemical properties of the photosensitizer, its uptake and the precise subcellular site where this event occurs.

Porphyrins and its derivatives are the most studied photosensitizers, due to the favourable wavelength, absorption characteristics and low intrinsic toxicity [8]. One of the most widely used photosensitizer, Photofrin ${ }^{\circledR}$, is a complex mixture of porphyrins that was approved by FDA for the treatment of oesophageal cancer and non-small cell lung cancer and presents several disadvantages [9]. Another very effective photosensitizer is Temoporfin which is a tetraaryl reduced porphyrin (chlorin) with very favourable absorption wavelength and with hydroxyl groups which assure some solubility in aqueous environment.

Tetraarylporphyrins with hydroxyl substituents in the phenyl groups proved to be particularly active [10-12] but diarylporphyrins prove to be advantageous, being less voluminous molecules with lower molecular weight that can allow higher uptake and quicker clearance [12-14].

Encouraging preclinical results were reported by Serra and co-workers $[13,15]$ in which a series of tetraaryl and diaryl-substituted hydroxyl substituted porphyrins with halogen groups show high phototoxicity in the in vitro preliminary screening. In the present study we focus on the most active compounds from these studies, which structures are presented in Fig. 1, and evaluate tumour regression in an animal model based in Balb/c nu/nu mice. Also some aspects of its in vitro and ex vivo activities against human colon adenocarcinoma and melanoma are accessed.

\section{Materials and methods}

\section{Chemicals}

The synthesis of 5,10,15,20-tetrakis(2-bromo-5hydroxyphenyl)porphyrin (TBr4) and 5,15-bis(2-bromo5-hydroxyphenyl)porphyrin (BBr2) (see structure in Fig. 1) was prepared as previously described $[13,15]$.

\section{Cells and culture conditions}

The human cell lines of colorectal adenocarcinoma, WiDr, melanoma, A375, and skin fibroblasts, HFF1, were obtained from American Type Culture Collection (ATCC) and passaged for less than 22 times to perform all studies. The cell lines were maintained in accordance with ATCC recommendations in DMEM medium (Sigma) supplemented with 10\% FBS (Gibco) at $37^{\circ} \mathrm{C}$ in a $95 \%$ air and $5 \% \mathrm{CO}_{2}$ atmosphere, in a humidified incubator. For all studies, cells were detached using a solution of $0.25 \%$ trypsin-EDTA (Gibco).

\section{Subcellular localization}

WiDr cells were plated in multiwells in which cover-slips were previously introduced and left in the incubator overnight to allow attachment of the cells. Cultures were incubated for $24 \mathrm{~h}$ with $5 \mu \mathrm{M} \mathrm{TBr} 4$ or BBr2. Plates were washed with phosphate buffer saline (PBS; in $\mathrm{mM}: 137 \mathrm{NaCl}$, $2.7 \mathrm{KCl}, 10 \mathrm{Na}_{2} \mathrm{HPO}_{4}$, and $1.8 \mathrm{KH}_{2} \mathrm{PO}_{4}[\mathrm{pH} \mathrm{7.4])} \mathrm{and} \mathrm{labelled}$ with MitoTracker Green FM, according to supplier recommendations. After, cells were fixed with methanol/acetone $(1: 1)$ at $4{ }^{\circ} \mathrm{C}, 10 \mathrm{~min}$, and incubated with $5 \mu \mathrm{g} / \mathrm{mL}$ Hoechst33252 (Sigma), for $10 \mathrm{~min}$ in the dark. Cover-slips were placed on slides using mounting medium Glycergel (Dako). Observations and image acquisition were made on a Motic AE31 system microscope equipped with epifluorescence Motic AE31 EF-INV-II. For observation of the sensitizers the excitation filter was $540 \pm 25 \mathrm{~nm}, 565 \mathrm{~nm}$ beam splitter and emission filter of $605 \pm 55 \mathrm{~nm}$. Images were acquired in a 5000 Cooled Motic camera coupled to computer with the software Motic Images Advanced 3.2.

\section{Cytotoxicity studies}

A375 and WiDr cells were incubated with several concentrations of sensitizers, ranging from $50 \mathrm{nM}$ to $10 \mu \mathrm{M}$. After $24 \mathrm{~h}$ incubation medium was replaced by sensitizer-free medium and cultures were irradiated with a flux of $7.5 \mathrm{~mW} / \mathrm{cm}^{2}$ until a total of $10 \mathrm{~J}$ was achieved, using a light source equipped with a red filter ( $\lambda$ cut off $<560 \mathrm{~nm}$ ). In all tests two controls were performed: untreated cultures and cultures treated with the vehicle of administration of sensitizers: $\mathrm{H}_{2} \mathrm{O} / \mathrm{PEG}_{400} / \mathrm{EtOH}(50 / 30 / 20, \mathrm{v} / \mathrm{v} / \mathrm{v})$. The analysis of cell proliferation was made $24 \mathrm{~h}$ after irradiation for both cell lines. WiDr cells were also evaluated after 48 and $72 \mathrm{~h}$.

Sensitizers' cytotoxicity was evaluated in the dark. Cell proliferation analysis was made $24 \mathrm{~h}$ after administration of sensitizers, without irradiation. In order to check whether there are differences in response to treatment to the 

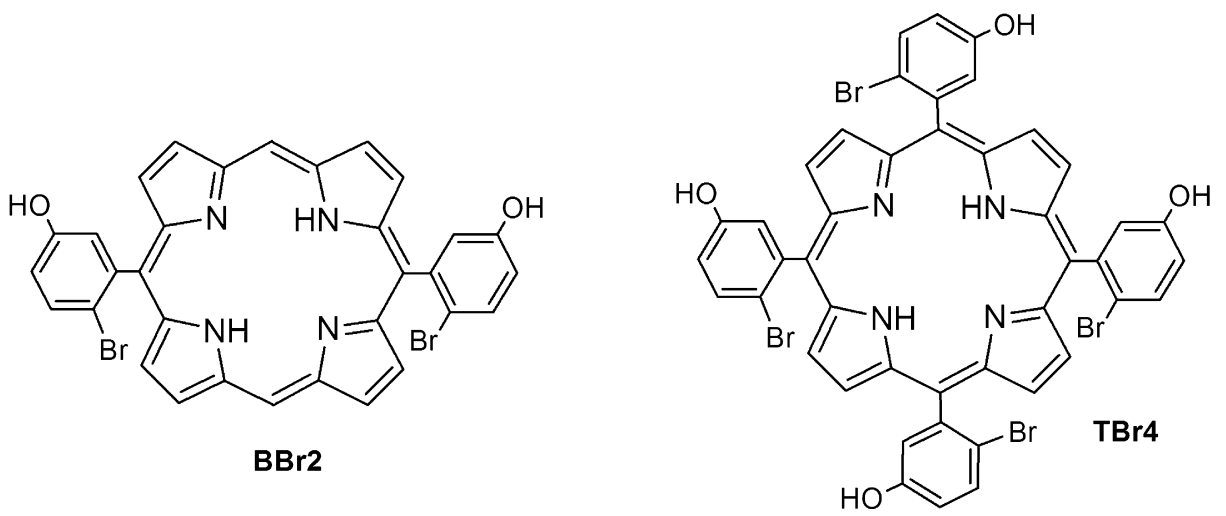

Figure 1 Chemical structure of the sensitizers 5,10,15,20-tetrakis(2-bromo-3-hydroxyphenyl)porphyrin (TBr4) and 5,15-bis(2bromo-3-hydroxyphenyl)porphyrin (BBr2).

photosensitizers between tumour and non-tumour cells, cell proliferation studies were performed in the human non-tumour cells HFF1 according to the same procedure.

For the evaluation of cell proliferation the MTT assay was performed [16]. Briefly, cell cultures were submitted to a solution of 3-(4,5-dimethylthiazol-2-yl)-2,5diphenyltetrazolium bromide $(0.5 \mathrm{mg} / \mathrm{mL}$, Sigma) in PBS, $\mathrm{pH}$ 7.4 , in the dark at $37^{\circ} \mathrm{C}$ for $4 \mathrm{~h}$. To solubilise formazan crystals, a $0.04 \mathrm{M}$ solution of hydrochloric acid in isopropanol was added and absorbance was measured using an SLT-Spectra spectrophotometer. Cytotoxicity was expressed as the inhibition percentage in cultures subjected to PDT correlated with cultures treated only with the vehicle administration of sensitizers. This procedure allowed us to establish dose-response curves, obtained using Origin 8.0, and to calculate the concentration of sensitizers that inhibits the proliferation of cultures in $50 \%$ (IC50).

\section{Viability and cell death}

WiDr and $\mathrm{A} 375$ cell cultures were incubated for $24 \mathrm{~h}$ with $\mathrm{TBr} 4$ or $\mathrm{BBr} 2$ in the concentration of $1 \mu \mathrm{M}$. After, the cultures were irradiated until $10 \mathrm{~J}$. Flow cytometry analysis was performed $24 \mathrm{~h}$ after PDT. WiDr cells were also analysed 48 and $72 \mathrm{~h}$ after treatment. Controls were performed on every test. Cell viability was accessed using annexin- $V$ and propidium iodide incorporation $[17,18]$. Cells were labelled with allophycocyanin conjugate annexin- $\mathrm{V}$ (BD Biosciences) and propidium iodide (Immunstep) as described by the supplier. Cells were analysed using an excitation wavelength of $525 \mathrm{~nm}$ and $640 \mathrm{~nm}$. This analysis was performed in triplicate using a six-parameter, four-color FACSCalibur flow cytometer (Becton Dickinson). For each assay $10^{6}$ cells were used and data on at least 10,000 events was collected using Cell Quest Software (Becton Dickinson) and analysed using PaintA-Gate software (Becton Dickinson). Results are expressed in percentage of apoptotic, late apoptotic/necrotic, necrotic and viable cells.

\section{Mitochondrial membrane potential}

The mitochondrial membrane potential was determined using a fluorescent probe, JC-1 (1st
J-aggregate-forming cationic; 5, 5',6,6'-tetrachloro$1,1^{\prime}, 3,3^{\prime}$-tetraethylbenzimidazol carbocyanine). The mitochondrial membrane potential determines the selective uptake of JC-1 by mitochondria, emitting fluorescence at different wavelengths. When the membrane potential is high, aggregate formation is preferential and red fluorescence $(590 \mathrm{~nm})$ is emitted. In turn, as the mitochondrial membrane potential decreases, or in cases in which the membrane is depolarized, JC-1 form monomers that emit green fluoresce $(529 \mathrm{~nm})$. Thus, the ratio of green and red fluorescence, usually named monomers/aggregates (M/A) ratio, provides an estimate of mitochondrial membrane potential [19]. WiDr and A375 were treated as described and analysed $24 \mathrm{~h}$ after treatment, being WiDr cells analysed also 48 and $72 \mathrm{~h}$ later. Cells were incubated with $5 \mathrm{mg} / \mathrm{mL}$ of $\mathrm{JC}-1$ (Invitrogen) for $15 \mathrm{~min}$ at $37^{\circ} \mathrm{C}$, in the dark and detection was performed. The results are expressed as mean fluorescence intensity (MIF) and the monomers/aggregates $(\mathrm{M} / \mathrm{A})$ ratio was calculated.

\section{Evaluation of ROS production}

WiDr and A375 were treated as described and analysed $24 \mathrm{~h}$ after treatment, being WiDr cells analysed also 48 and $72 \mathrm{~h}$ later. The expression of intracellular peroxides was determined using the probe $2^{\prime}, 7^{\prime}$-dichlorodihydrofluorescein diacetate (DCFH2-DA) [20,21]. A cell suspension with approximately $10^{6}$ cells was incubated for $45 \mathrm{~min}$ in the dark at $37^{\circ} \mathrm{C}$ with $5 \mu \mathrm{M}$ of DCFH2-DA (Invitrogen). After washing, detection was performed with the excitation and emission wavelengths of 504 and $529 \mathrm{~nm}$, respectively. The production of superoxide was assessed using $5 \mu \mathrm{M}$ dihydroethidium (DHE) probe [22], 10 min incubation at room temperature without light. Detection was performed using the excitation wavelength of $620 \mathrm{~nm}$.

\section{In vivo studies}

Six- to eighth-weeks-old male athymic nude mice (Balb/c $\mathrm{nu} / \mathrm{nu}$ ), with $18-22 \mathrm{~g}$ weight, were purchased from Charles River Laboratories) and housed under conditions in accordance with the Institution of Animal Care of the University of 
Coimbra and European Community. The study was approved by the Ethics committee.

The animal model used was based in Balb/c nu/nu, a strain of athymic mice, where xenotransplants were obtained by injection of $4 \times 10^{6}$ cells (A375 or WiDR) in the dorsal region. Tumours were monitored in order to check its volume according to the following expression: $V=\left(L \times S^{2}\right) / 2$, where $L$ is the largest axis of the tumour and the smallest axis is $S[23,24]$. When tumour volume reached $300-500 \mathrm{~mm}^{3}$, the sensitizers $(2 \mathrm{mg} / \mathrm{kg})$ were administered intraperitoneally.

The animals were divided into three experimental groups that differed in time at which the tumours were irradiated, respectively 24,48 and $72 \mathrm{~h}$ after each sensitizer administration. For irradiation the animals were subjected to the effect of a solution of $77 \%$ of ketamine $\left(\right.$ Ketalar $^{\circledR}$, ParkeDavis) and 23\% chlorpromazine (Largactil ${ }^{\circledR}$, Laboratórios Vitória). The animals were irradiated, in the tumour area, using a laser light with a power of $0.13 \mathrm{~W}$ until $180 \mathrm{~J}$ was reached. The control group consisted of animals irradiated in the same conditions but without administration of sensitizers.

Monitoring of tumours was carried out every $48 \mathrm{~h}$ during 12 days. Dimensions of the tumour were assessed in order to calculate the volume change in relation to original dimensions, according to the formula $V T R=V(x) / V(0)$, where VTR is the relative tumour volume, $V(x)$ the tumour volume obtained on evaluation and $V(0)$ the tumour volume obtained immediately before irradiation [25].

\section{Tumour histology}

After 12 day follow up, animals were sacrificed and tumours excised and preserved in $10 \%$ formalin. Afterwards, tumour samples were dehydrated in increasing concentrations of alcohol, cleared in xylene and embedded in paraffin. Random microtomy was performed and slides were prepared and stained with haematoxylin-eosin (H\&E), a routine procedure appropriate to distinguish cell morphology, evaluate pathology and cell viability. Microscopic observation was performed on a Nikon microscope equipped with ACT-1 Nikon digital camera and dedicated computer DMXM120F with the Nikon Eclipse 80i. All histology was performed by a single experienced histopathologist (L. Carvalho) blinded to the treatment category. For each sample an independent report was performed and the presented results correspond to the summary of the all reports obtained for each condition.

\section{Statistics}

Statistical analysis was performed using SPSS version 17. Flow cytometry results were analysed by the nonparametric Mann-Whitney test. For the prospective study, the estimation of Kaplan-Meier to construct survival curves was performed. An event occurred if the tumour volume was below the lower limit of the confidence interval $95 \%$ to the average tumour volumes in mice in the control group. For each sensitizer four survival curves were built, one for the control group and three on each of time of incubation. The comparison of curves was performed by the Wilcoxon test and median time of survival was determined. Multiple pair-wise comparisons were made when statistically significant differences were observed among the four survival curves. Here we used the Wilcoxon test, adjusted by the Bonferroni method. A significance of $5 \%$ was considered for all comparisons.

\section{Results}

\section{Subcellular localization}

Fluorescence microscopy studies performed in colorectal adenocarcinoma cell line showed that the pattern of distribution of $\mathrm{TBr} 4$ and $\mathrm{BBr} 2$ coincide with the location of the mitochondrial probe, Fig. 2. Fig. 2 also evidence that sensitizers are not localized in the nucleus, since there was no fluorescence in the nuclear area, stained with Hoechst.

\section{Cytotoxicity studies}

Fig. 3(B) represents $\mathrm{BBr} 2$ and $\mathrm{TBr} 4$ dose-response curves. The IC50 values are presented in Table 1. The dibrominated porphyrin $\mathrm{BBr} 2$ is more active than the tetrabrominated derivative. For colorectal adenocarcinoma cells, treatment using a concentration of $464 \mathrm{nM} \mathrm{TBr4}$ achieves the IC50, while for BBr2 only $180 \mathrm{nM}$ is needed, less than half the concentration. Melanoma cells, with an IC50 of $100 \mathrm{nM}$ for $\mathrm{BBr} 2$ and $50 \mathrm{nM}$ for $\mathrm{TBr} 4$, are more susceptible to both sensitizers. For colorectal adenocarcinoma cells, the analysis was also performed over time allowing us to observe a decrease of the IC50 with $\mathrm{BBr} 2$ sensitizer to about $140 \mathrm{nM}$. For TBr4 the contrary was observed with the IC50s of $620 \mathrm{nM}$ and $765 \mathrm{nM}$ for 48 and $72 \mathrm{~h}$ of evaluation, respectively. Related to the experiments in the absence of the light exposure step, performed in tumour and non-tumour cells, IC50 values, are higher than $4 \mu \mathrm{M}$.

\section{Viability and cell death}

For melanoma, treatment induces a decrease in the population of living cells, $\mathrm{BBr} 2: p=0.025$ and $\mathrm{TBr} 4: p=0.025$, in relation to control populations and, on the contrary, necrotic, BBr2: $p=0.024$ and TBr4: $p=0.024$, and late apoptotic populations, BBr2: $p=0.024$ and $\mathrm{TBr} 4: p=0.024$, are increased, as represented in Fig. 3(A). Populations treated with $\mathrm{BBr} 2$ versus treated with $\mathrm{TBr} 4$ shows differences only for living cells, $p=0.016$.

For colorectal adenocarcinoma, in TBr4 treated, a lower population of living cells, $p=0.023$, and higher necrotic population, $p=0.008$, were observed. Regarding $B B r 2$ sensitizer, treatment introduced an increase of necrosis, $p=0.004$, and a decrease of living cells, $p=0.004$. Comparing sensitizers, in TBr4 the population of living cells is significantly higher, $p=0.027$. The $48 \mathrm{~h}$ after treatment analysis showed few differences between control and $\mathrm{TBr} 4$ treated cells, being increased the population in late apoptosis/necrosis, $p=0.025$. However, with $\mathrm{BBr} 2$ treatment there was a significant increase in populations of necrotic, $p=0.014$ and apoptotic cells, $p=0.014$ and a decrease of living cells, $p=0.014$. At $72 \mathrm{~h}$, treatment with $\mathrm{BBr} 2$ altered the populations of living cells, $p=0.046$, and necrotic cells, $p=0.011$. 

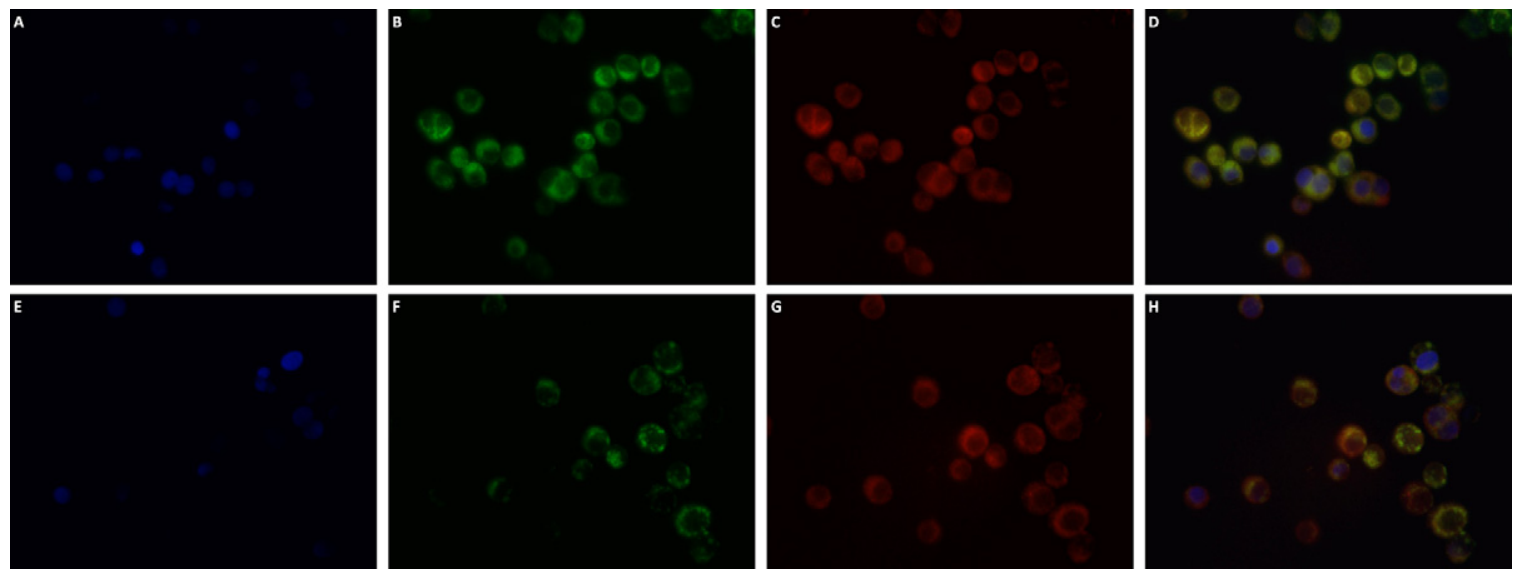

Figure 2 Subcellular localization of the sensitizers BBr2 and TBR4 in WiDr cell line. Fluorescence microscopy images obtained with a magnification of $400 \times$. Subcellular localization of each photosensitizer (C, BBr2; G, TBr4), of the mitochondrial probe MitoTracker Green FM (B, F) and nuclei stained with Hoechst 33252 (A, E). Merge of images (D, H).

\section{Mitochondrial membrane potential}

Mitochondrial membrane depolarization was observed $24 \mathrm{~h}$ after treatment in colon adenocarcinoma cells (Fig. $3(C)$ ), TBr4: $p=0.002$ and BBr2: $p=0.002$; and melanoma cells (Fig. $3(D))$, TBr4: $p=0.022$ and BBr2: $p=0.022$. Analysis performed later in time for colon adenocarcinoma proved a significant mitochondrial disruption with $\mathrm{BBr} 2$ sensitizer $48 \mathrm{~h}: p=0.037$ and $72 \mathrm{~h}: p=0.037$ while for TBr4 cells recover mitochondrial potential. Comparison of treatment with the sensitizers showed higher damage for $\mathrm{BBr} 2, p=0.009$, at $24 \mathrm{~h}$.

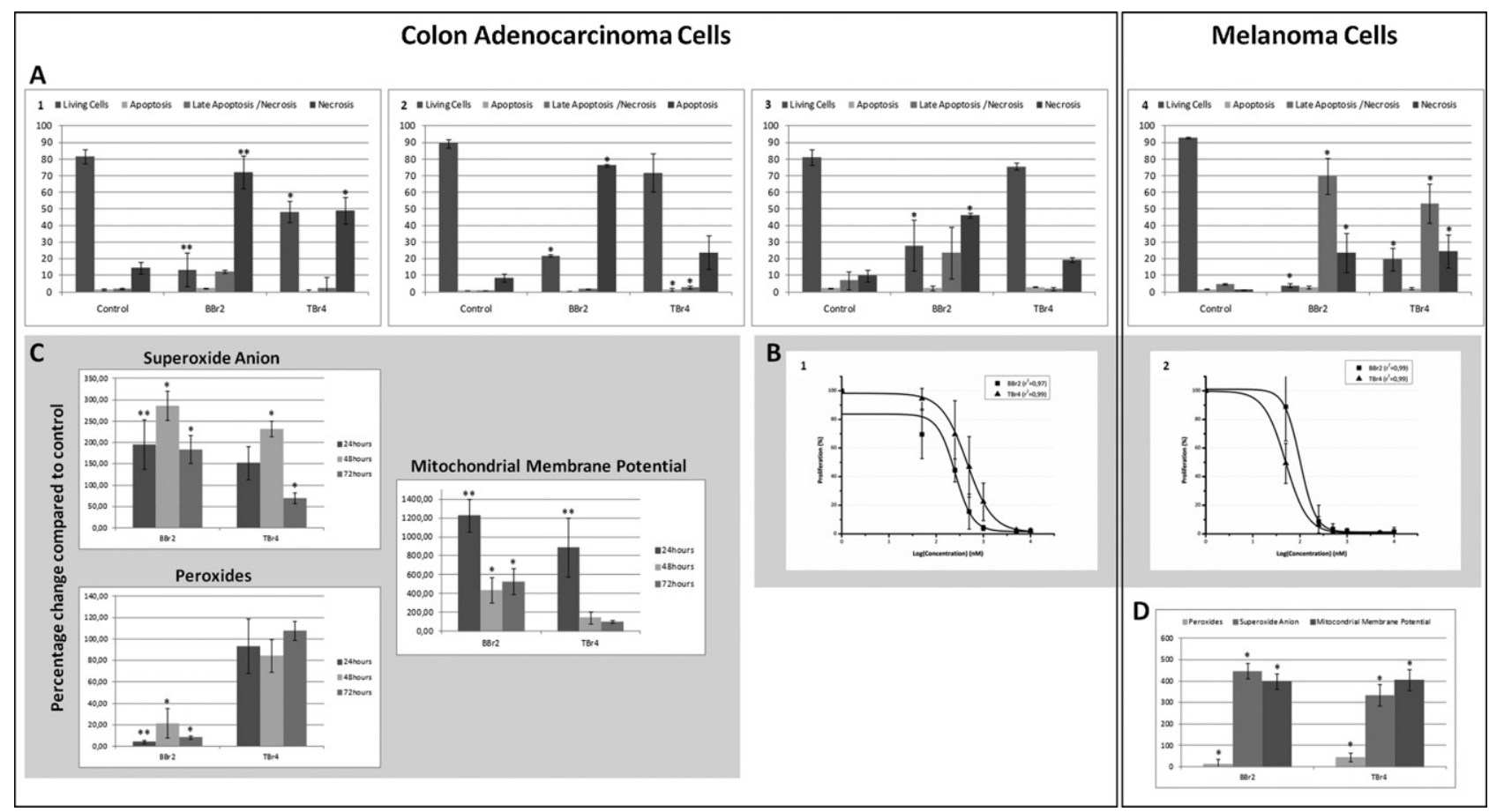

Figure 3 Outcome of $\mathrm{BBr} 2$ and TBr4 based PDT in vitro. (A) Cell viability. The results represent the percentage of viable cells, cells in apoptosis, cells in late apoptosis/necrosis and cells in necrosis; 1, 2 and 3: colon adenocarcinoma cells analysed 24, 48 and $72 \mathrm{~h}$ after treatment, respectively; 4: melanoma cells A375 analysed $24 \mathrm{~h}$ after treatment. (B) Dose-response curves of cell cultures, analysis performed $24 \mathrm{~h}$ after treatment; 1 : colon adenocarcinoma cell cultures; 2 : melanoma cell cultures. (C and D) Intracellular production of ROS and alteration of mitochondrial membrane potential for colon adenocarcinoma and melanoma, respectively. ( $A, C$ and $D$ ) The error bars represent the standard error calculated for at least three independent experiments. The ${ }^{*}$ represent significant differences between the respective control population. Statistical significance: ${ }^{*} p<0.05 ;{ }^{* *} p<0.01$. (B) The results represent the average and standard deviation of at least six independent experiments. 
Table 1 IC50 of BBr2 and TBr4 sensitizers. The IC50 of the sensitizers was calculated $24 \mathrm{~h}$ after treatment for colorectal adenocarcinoma WiDr cells and melanoma A375 cells. For WiDr cells evaluation was also performed 48 and $72 \mathrm{~h}$ after treatment. The IC50 of experiments where irradiation was omitted, including HFF1 cells, is also presented.

\begin{tabular}{|c|c|c|c|c|c|c|c|}
\hline & \multicolumn{4}{|c|}{ PDT (10J) } & \multicolumn{3}{|c|}{ Dark experiments } \\
\hline & \multicolumn{3}{|l|}{ WiDr } & \multirow{2}{*}{$\begin{array}{l}\text { A375 } \\
24 \mathrm{~h}\end{array}$} & \multirow{2}{*}{$\begin{array}{l}\text { WiDr } \\
24 \mathrm{~h}\end{array}$} & \multirow{2}{*}{$\begin{array}{l}\mathrm{A} 375 \\
24 \mathrm{~h}\end{array}$} & \multirow{2}{*}{$\begin{array}{l}\text { HFF1 } \\
24 \mathrm{~h}\end{array}$} \\
\hline & $24 \mathrm{~h}$ & $48 \mathrm{~h}$ & $72 \mathrm{~h}$ & & & & \\
\hline $\mathrm{BBr} 2$ & $180 \mathrm{nM}$ & $142 \mathrm{nM}$ & $141 \mathrm{nM}$ & $100 \mathrm{nM}$ & $7.08 \mu \mathrm{M}$ & $4.38 \mu \mathrm{M}$ & $7.07 \mu \mathrm{M}$ \\
\hline$r^{2}$ & 0.97 & 0.99 & 0.90 & 0.99 & 0.93 & 0.99 & 0.96 \\
\hline TBr4 & $464 \mathrm{nM}$ & $620 \mathrm{nM}$ & $765 n M$ & $49.7 \mathrm{nM}$ & $>10 \mu \mathrm{M}$ & $4.91 \mu M$ & $8.07 \mu \mathrm{M}$ \\
\hline$r^{2}$ & 0.99 & 0.99 & 0.98 & 0.99 & - & 0.96 & 0.62 \\
\hline
\end{tabular}

\section{Evaluation of ROS}

PDT based on BBr2 and $\mathrm{TBr} 4$ induces several alterations in the intracellular production of ROS (Fig. 3). In melanoma cells there is a decrease in peroxide production for $\mathrm{TBr} 4$ : $p=0.024$ and $\mathrm{BBr} 2: p=0.024$, and an increase in superoxide anion production, TBr4: $p=0.022$ and $\mathrm{BBr} 2: p=0.022$. In colon adenocarcinoma, BBr2-PDT induces a decrease in peroxide production, $p=0.005$ and an increase in superoxide anion production, $p=0.005$. However, with $\mathrm{TBr} 4$ differences are not observed. Also, we found a decrease in peroxide production using BBr2 for analysis at $48 \mathrm{~h}, p=0.017$, and $72 \mathrm{~h}$, $p=0.037$. However, related to superoxide anion, BBr2-PDT induces an increase at $48 \mathrm{~h}: p=0.037$ and $72 \mathrm{~h}: p=0.014$, and TBr4 also increases superoxide anion at 48: $p=0.037$ and 72: $p=0.014$.

The comparison of colorectal adenocarcinoma cells treated revealed a trend towards a higher production of peroxides for $\mathrm{TBr} 4, p=0.009$ at $24 \mathrm{~h}$, and a higher production of superoxide anion for $\mathrm{BBr} 2$ at $72 \mathrm{~h}, p=0.021$. The comparison of melanoma cells treated showed that $\mathrm{BBr} 2$ induces a higher production of superoxide anion, $p=0.008$ ( $24 \mathrm{~h}$ evaluation).

\section{Animal studies}

The Kaplan-Meier curves represented in Fig. 4(I) show the follow-up of colon adenocarcinoma xenografts. We observed 31 events $(73.8 \%)$, considering the 42 cases. BBr2 induced a significant decrease in tumour growth, $p<0.001$. The most effective treatment was irradiation $72 \mathrm{~h}$ after $\mathrm{BBr} 2$ administration, $p=0.006$, with a significant decline in growth just in the second day of monitoring. For the $48 \mathrm{~h}$ protocol, there was also a significant decrease of tumour growth, $p=0.03$. Median survival times were 4,2 and 2 days for the treatments of 24,48 and $72 \mathrm{~h}$ respectively.

For $\mathrm{TBr} 4$ the existence of very significant differences between irradiated groups and the control group was verified, $p=0.009$. For each irradiation time were also observed differences comparing to control concerning $24 \mathrm{~h}: p=0.006$, $48 \mathrm{~h}: p=0.03$ and $72 \mathrm{~h}: p=0.006$. Between each of the three groups treated there is no difference, and the median survival time was 6, 2 and 4 days respectively. For this type of tumour PDT significantly reduces tumour growth. Although no significant differences were found between the two sensitizers stands $\mathrm{BBr} 2$ treatment with irradiation at $72 \mathrm{~h}$, for which there are five in six events on the second day of follow-up.

For melanoma xenografts (Fig. 4(I)), we found 23 events (46.9\%), considering the 49 cases. For the sensitizer $\mathrm{BBr} 2$ there was a significant decrease in tumour growth, $p=0.001$, in treated mice. The most effective treatment consists of irradiation $24 \mathrm{~h}$ after administration of sensitizer, $p=0.006$, with a significant decline in growth in the second day for every cases. After irradiation, 48 and $72 \mathrm{~h}$, there was also a significant decrease of tumour enlargement, $p=0.002$ and $p=0.024$, respectively. The median survival time was 2 days for all treatments.

For TBr4 very significant differences between irradiated groups and the control group was verified, $p=0.009$. Although for each irradiation time were observed differences from the control only at $72 \mathrm{~h}, p=0.006$. Median survival time was 6,2 and 4 days, for 24,48 and $72 \mathrm{~h}$, respectively. For melanoma, treatment significantly reduces tumour growth, being $\mathrm{BBr} 2$ the most effective sensitizer.

\section{Tumour histology}

In colorectal adenocarcinoma tumours excised from mice in the control group, were observed subcutaneous tumour nodules, $14-20 \mathrm{~mm}$, made of solid, trabecular and tubular structures of neoplastic cells with morphology of adenocarcinoma, as shown in Fig. 4. At the periphery solid pattern of cells with high mitotic rates is observed and at the centre necrosis which represents $30-80 \%$ of tumour volume is seen, outlining the formation of macro structures and microtubes.

Sections of tumours treated with $\mathrm{BBr} 2$ reflect the histological structure of well-differentiated adenocarcinoma with micro-and macro-glandular structures. Tumour nodules, $5-30 \mathrm{~mm}$, have central necrosis that occupies $10-50 \%$ tumour volume. The tissue consists of massive and trabeculae of neoplastic cells focally where there are rough and acinar structures. Often, adjacent to areas of necrosis are observed the formation of tubular structures. There were also solid areas with high mitotic rates.

TBr4 treated tumours $9-20 \mathrm{~mm}$, correspond to little or moderately differentiated adenocarcinoma with, predominantly, peripheral microacinar solid pattern and central necrosis occupying $5-50 \%$ of tumour volume. As can be seen in the images of Fig. 4 the tumour tissue adjacent to the centre outlines the formation of acinar structures, 

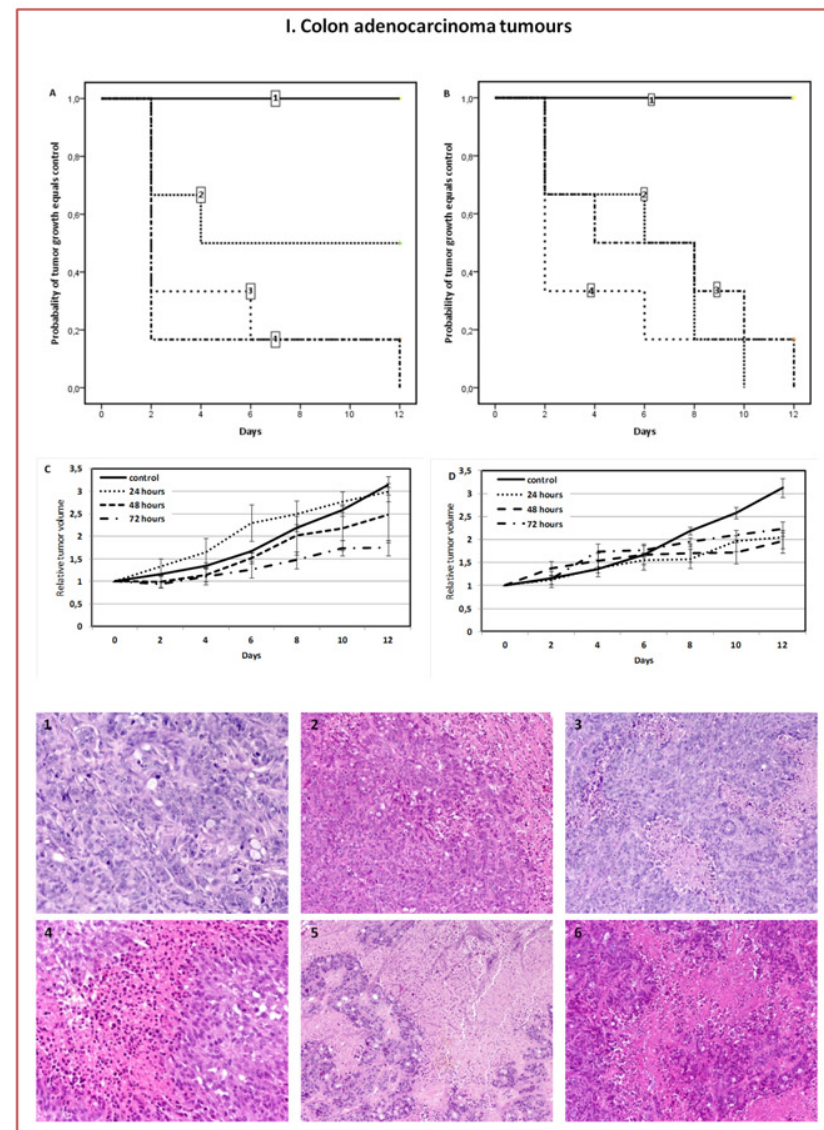

II. Melanoma tumours
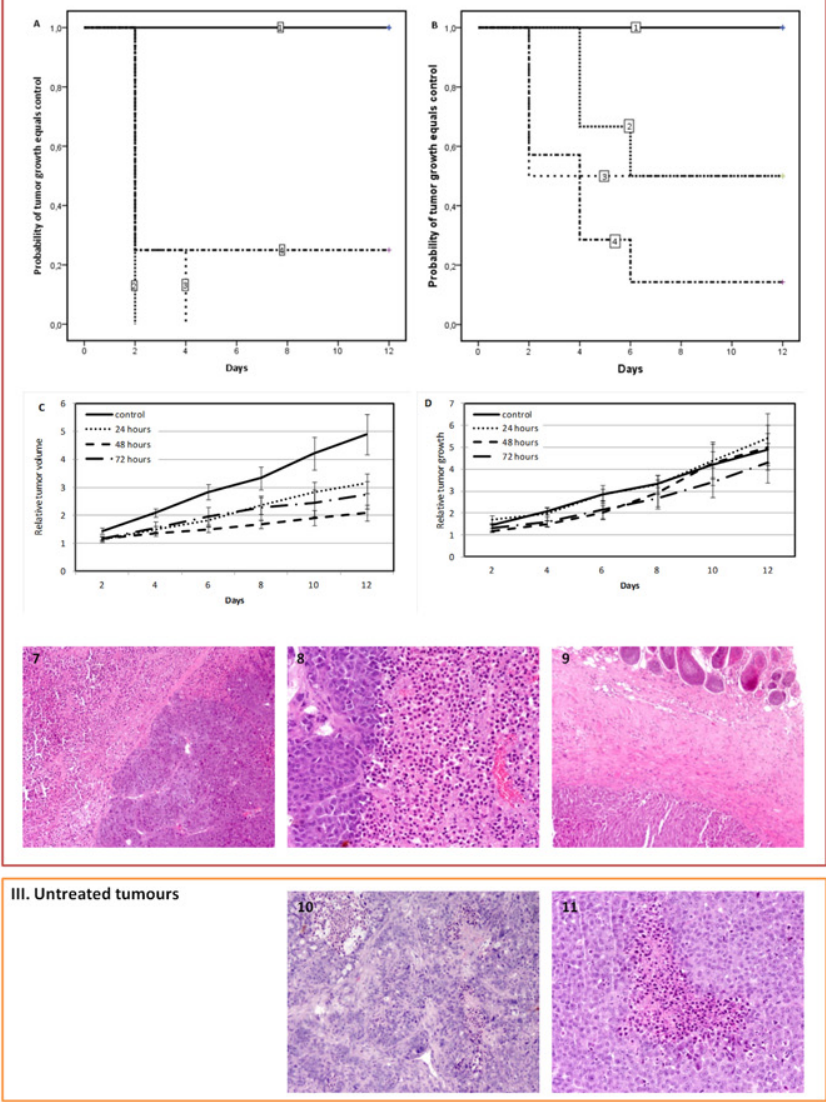

Figure 4 Growth of xenografts of human tumour cells. The Kaplan-Meier represents the likelihood of decreased tumour growth in response to $\mathrm{BBr} 2(\mathrm{~A})$ and $\mathrm{TBr} 4$ (B) PDT. Legend: 1: Control group; 2: Group of xenografts irradiated 24h after administration of sensitizer; 3: Group of xenografts irradiated $48 \mathrm{~h}$ after administration of sensitizer; 4: Group of xenografts irradiated $72 \mathrm{~h}$ after administration of sensitizer. The curves represent the growth rate of xenografts in response to PDT with $\mathrm{BBr} 2$ (C) and TBr4 (D). The error bars represent the standard error calculated for six animals in each group. Microphotographs represent histological sections of tumours, H\&E. 1: Cut of an adenocarcinoma irradiated $24 \mathrm{~h}$ after treatment with $\mathrm{BBr}$, histological structure in which the predominant solid pattern interrupted by areas of necrosis, $200 \times .2$ : Cut of an adenocarcinoma irradiated $48 \mathrm{~h}$ after treatment with $\mathrm{BBr} 2$, predominant solid pattern, $40 \times$. 3: Cut of an adenocarcinoma irradiated $72 \mathrm{~h}$ after treatment with $\mathrm{BBr}$, solid pattern interrupted by vast areas of necrosis, $100 \times .4$ : Cut of an adenocarcinoma irradiated $24 \mathrm{~h}$ after treatment with TBr4, solid pattern and necrosis, $200 \times$. 5: Cut of an adenocarcinoma irradiated $48 \mathrm{~h}$ after treatment with TBr4, acinar pattern and necrosis, $100 \times$. 6: Cut of an adenocarcinoma irradiated $72 \mathrm{~h}$ after treatment with TBr4, acinar pattern and necrosis, 100×. 7: Cut of a melanoma tumour irradiated $24 \mathrm{~h}$ after administration of $\mathrm{TBr} 4$, it is possible to distinguish the solid pattern tumour invaded by extensive areas of necrosis, 100x. 8: Cut of a melanoma tumour irradiated $48 \mathrm{~h}$ after administration of TBr4, 200×. 9: Cut of a melanoma tumour irradiated $72 \mathrm{~h}$ after administration of $\mathrm{TBr} 4,100 \times$. 10: Cut of an untreated adenocarcinoma, microacinar pattern, 100×. 11: Cut of an untreated melanoma, solid pattern with a small central area of necrosis, $100 \times$.

and periphery consists of massive and trabeculae of neoplastic cells with sketch of tubular formation. Tumour cells are large, with the nuclear/cytoplasm and high mitotic index.

Melanoma tumours from control mice have a solid pattern of large cells with high mitotic index and anisokaryosis. Nodules showed central necrosis that represented about $10 \%$ of tumour volume. Treated tumours were well differentiated carcinomas with bigger axis $12-23 \mathrm{~mm}$ with a solid pattern of large cells disposed like a syncytium with high nuclei/cytoplasm ratio and anisokaryosis. In the periphery, cells present high mitotic index and central necrosis correspond to $10-50 \%$ of the tumour volume.

\section{Discussion}

Porphyrin compounds are the most studied compounds as sensitizers in PDT and hydroxyl substituted ones already proved good activity [10]. Diaryl sensitizers with two hydroxyl groups in each phenyl ring showed promising results against colon adenocarcinoma xenografts [26,27]. The hydroxyl groups in meta position of phenyl rings (meso position) reinforce this activity better than in positions ortho or para [12,28]. In addition, hydroxyl meta substituted tetraphenylporphyrins have a preferential localization in tumour tissue $[11,28]$. One of the most active 
photosensitizer in clinical use, Foscan ${ }^{\circledR}$, also has a substitution of hydroxyl groups in meta position of the phenyl groups. This best performance must be due to better solubility of these molecules in aqueous media [12].

Halogenated porphyrins have also been studied as sensitizers in PDT, confirming heavy atom effect, i.e., the largest capacity of production of singlet oxygen by halogen substituted sensitizers $[29,30]$. Bromination in porphyrins favours ROS formation by increasing the formation of triplet state and singlet oxygen generation. Concerning this and our previous work, it became pertinent a more detailed study of the photodynamic properties of hydroxyphenylporphyrins with bromine atoms $\mathrm{TBr} 4$ and $\mathrm{BBr} 2$, comparing the tetraaryl compound with the corresponding diaryl.

Photodynamic reaction depends largely of uptake, retention and accumulation of sensitizers in tumour tissue. Subcellular localization of sensitizers defines the site of primary damage since the first places to suffer the damage of photodynamic reaction is the closest to the place of singlet oxygen formation [31-33]. As described [34], mitochondria of WiDr cell line show a granular appearance that, as we can see in Fig. 2, has a similar distribution pattern of the bright red fluorescence of the cells stained by sensitizers. Thus, BBr2 and TBr4 seem to be located predominantly in the mitochondria. This was not a surprise once porphyrins and derived macrocycles are lipophilic molecules that tend to accumulate in membrane organelles such as mitochondria or lysossomes $[35,36]$. Also, it was described that between tetrapyrrole compounds, the most effective sensitizers and brominated porphyrins tend to accumulate in mitochondria [37-39]. Mitochondrial damage is considered the major consequence of phototoxicity [32]. The first event, that occur a few seconds after photosensitization, is the release of cytochrome- $\mathrm{C}$ from the mitochondrial intermembrane space to the cytosol and the dissipation of mitochondrial membrane potential $[32,40]$.

Dose-response curves present in Fig. 3 show that phototoxicity increases with increasing sensitizers' concentration. For the two tested photosensitizers the melanoma cells A375 were more susceptible to treatment than the adenocarcinoma cell line WiDr. The diarylphotosensitizer $(\mathrm{BBr} 2)$ is more active in the inhibition of cell proliferation than the tetraarylderivative $\mathrm{TBr} 4$. But, most important, the experiments performed in colorectal adenocarcinoma cells show that the IC50 of $\mathrm{BBr} 2$ decreases at $48 \mathrm{H}$ compared to $24 \mathrm{~h}$ to about $140 \mathrm{nM}$. However, for the compound tetraaryl TBr4 there is an increase in the value of IC50 to 620 and $765 \mathrm{nM}$, at 48 and $72 \mathrm{~h}$ respectively. Therefore, we concluded that treatment with $\mathrm{TBr} 4$ does not introduce irreversible changes in the cell which is able to recover from the damages caused by treatment. Previous work by Banfi et al. also show that diarylporphyrins are much more active than corresponding tetraarylporphyrins [12].

Evaluation of cytotoxicity in the dark proved that light activation is fundamental for cytotoxic activity. Evaluation of cytotoxicity in fibroblast cells showed that IC50 are achieved at high concentrations (BBr2: $7.07 \mathrm{mM}$ and $\mathrm{TBr} 4$ : $8.07 \mathrm{mM}$ ) very superior to therapeutic concentrations, confirming the low toxicity of these compounds in normal cells where light activation does not occur.

The MTT test report about proliferative capacity and mitochondrial function, but does not show changes that lead to activation of death pathways. PDT can activate different cell death pathways: apoptosis, necrosis and autophagy. The type and percentage of cell death pathways depends of photosensitizer characteristics, oxygen concentration, wavelength, intensity of light and also cell type [33].

Treatment with $\mathrm{BBr} 2$ and $\mathrm{TBr} 4$ induces significant or very significant reduction of viable cell populations and growth of cell populations where death pathways were activated. In melanoma cells there is an increase of the populations in late apoptosis and necrosis for both sensitizers and in colon adenocarcinoma only the necrotic population is increased. The melanoma cells A375, as already seen in proliferation studies were more susceptible to treatment. For both cell lines, the population of live cells after BBr2 treatment is significantly lower than after $\mathrm{TBr} 4$ treatment, which confirms the best action of diaryl sensitizer.

In what concerns viability, treatment evaluation over time in colorectal adenocarcinoma cells also shows an interesting aspect. With TBr4 the population of living cells at $48 \mathrm{~h}$ is higher than at $24 \mathrm{~h}$, and the population of viable cells at $72 \mathrm{~h}$ is greater than $48 \mathrm{~h}$ and is almost equal to control cultures. Thus, treatment with $\mathrm{TBr} 4$ shows increased viability over time suggesting that the treatment is not effective and there is a tendency for recovery of the WiDr cells. However, with $\mathrm{BBr} 2$ treatment the opposite is observed with a reduction of the IC50 over time and of the population of viable cells.

Therefore in vitro studies showed that $\mathrm{BBr} 2$ is the most effective sensitizer and, the predominant death pathway activated is necrosis. Interestingly, some of the work published with porphyrin derivative-based PDT induces death primarily by apoptosis [32,41]. Cell death induced by PDT alternates between apoptosis and necrosis according to light intensity during treatment, producing quick cell lyses instead of programmed cell death if the photodynamic stimulus is severe $[33,42-44]$. This is pointed in works were human melanoma cells A375 were used [45]. In the present study cell cultures were subjected to a total energy of $10 \mathrm{~J}$ with a power of $7.5 \mathrm{~mW}$. In the future it would be pertinent to verify whether treatment with sensitizers studied using lower energies and powers activate the same pathways of death.

However, it was also proven that the same sensitizer can induce different types of death according to the cell line where it is studied [31,32]. For the cell line HT29 colorectal adenocarcinoma regardless the intensity of PDT death occurs mainly by necrosis [44]. Mikes et al. suggested that this fact is related with a mutation associated with overexpression of $\mathrm{p53}$, probably due to the production of a more stable form, that balances cell death towards necrosis [44]. Interestingly, human colorectal adenocarcinoma HT29 and WiDr share a substitution on p53 protein where a histidine at position 273 is replaced by an arginine [46]. In this case, activation of death by necrosis can be also related the genetic profile of the WiDr cells and not only with photophysical and photochemical characteristics of sensitizers.

Although PDT protocols that promote apoptosis are recommended when PDT is applied in a curative manner, nowadays is known that death by necrosis is accompanied by activation of inflammatory and immune response $[47,48]$. This response not only favours the eradication of the tumour locally and can also have positive effects on tumours that 
have already infiltrated into the surrounding tissue or even in relation to tumour cells found away from the irradiated area $[40,44]$. For this reason a higher incidence of necrosis observed after PDT should not be a barrier to future clinical application.

Fluorescence microscopy studies showed that sensitizers accumulate mainly in mitochondria and, it is widely established that the place of accumulation of the sensitizer is the first target of action of PDT. So, mitochondrial involvement was evaluated and, as expected, after treatment high mitochondrial membrane depolarization occurs. The involvement of this organelle in the photodynamic reaction and disturbance of cell viability is notorious. Once more we confirm the best activity of BBr2 in the case of the human colon adenocarcinoma cells. Analysis during time brings an interesting finding: for $\mathrm{TBr} 4$ initial depolarization is not maintained over time while for $\mathrm{BBr} 2$ disruption maintains.

ROS play a central role in PDT. As shown in Fig. 3, a ROS imbalance occurs by diminishing of peroxides and augmentation of superoxide anion concentration. However looking specifically to $\mathrm{TBr} 4$ results we realize that this sensitizer has less influence in the equilibrium, it does not alters peroxides production and in what concerns superoxide anion production, influence is seen only later in time. We confirm that the tetraaryl sensitizer is less efficient in the production of ROS.

Once we verified that $\mathrm{BBr} 2$ and $\mathrm{TBr} 4$ have effect in vitro on proliferation and viability of colorectal adenocarcinoma and melanoma in vivo studies were performed. For each sensitizer were evaluated three treatment regimens that led to a significant decrease in tumour growth compared to untreated control groups. The interval between injection and irradiation influences the decrease in tumour growth and response to treatment is different for the sensitizers studied. These results are in agreement with those obtained from in vitro studies that indicate that the diarylporphyrine $\mathrm{BBr} 2$ is more effective than the tetraarylporphyrin. For colon adenocarcinoma xenografts $\mathrm{BBr} 2$ best results arise when radiation occurs $72 \mathrm{~h}$ after injection, however, even being more susceptible in all regimens of treatment, human melanoma A375 xenografts respond better for a $24 \mathrm{~h}$ period.

$\mathrm{BBr} 2$ and $\mathrm{TBr} 4$ have photodynamic effect in vivo at low concentrations compared with Photofrin ${ }^{\circledR}$, which was used in concentrations equal to or greater than $5 \mathrm{mg} / \mathrm{kg}$ to obtain PDT effect in xenografts of colorectal adenocarcinoma [49-51]. In HT29 xenografts, Photofrin ${ }^{\circledR}$ was used at a dose of $30 \mathrm{mg} / \mathrm{kg}$ [52].

After 12 days of follow-up was possible to excise the tumours and perform the histological analysis that confirmed the main pathway of death activated is necrosis. Given the roughly spherical geometry of the tumour, is common the existence of a core of non-viable cells. The peripheral cells have a more adequate blood supply, and often occur in the core apoptotic and/or necrotic cells and mostly a state of hypoxia [25]. In tumours of control group were able to identify this core of non-viable cells, which have suffered death by necrosis. However, histological analysis of xenografts undergoing PDT showed the presence of extensive areas of necrosis. In other studies with sensitizers with the basic structure of chlorin, histological analysis revealed that death induced was necrosis $[52,53]$.
PDT based on the use of sensitizers BBr2 and BBr4 have the ability to induce cell death by necrosis in cells of colorectal adenocarcinoma and melanoma in vitro and in vivo. Now we realized that both sensitizers have no cytotoxicity in the dark or in non-tumour cells at therapeutic concentrations and are more effective than the approved sensitizer Photofrin ${ }^{\circledR}$. The dyaril compound $\mathrm{BBr} 2$ is more efficient than the tetraaryl $\mathrm{TBr} 4$, in what concerns production of intracellular ROS, mitochondrial disruption and finally induction of effective cell death. Both sensitizers induce cell death by necrosis in vitro and in vivo. The animal studies showed that the formulations used did not produce side effects at concentrations that are administered and showed significant photodynamic effect in relatively low doses, being BBr2 the most effective. Now we consider that $\mathrm{BBr} 2$ is a molecule that should be the subject of extensive studies towards clinical use.

\section{Financial support}

This work was supported by The Foundation of Science and Technology (SFRH/BD/44957/2008) to Mafalda Laranjo.

\section{References}

[1] Agostinis P, Berg K, Cengel KA, et al. Photodynamic therapy of cancer: an update. Cancer Journal for Clinicians 2011;61:250-81.

[2] Serra A, Pineiro M, Pereira N, et al. A look at clinical applications and developments of photodynamic therapy. Oncology Reviews 2008;2:235-49.

[3] Allison R, Moghissi K, Downie G, Dixon K. Photodynamic therapy (PDT) for lung cancer. Photodiagnosis and Photodynamic Therapy 2011;8:231-9.

[4] Mroz P, Yaroslavsky A, Kharkwal GB, Hamblin MR. Cell death pathways in photodynamic therapy of cancer. Cancers 2011;3:2516-39.

[5] Castano A, Demidova T, Hamblin M. Mechanisms in photodynamic therapy: part one? Photosensitizers, photochemistry and cellular localization. Photodiagnosis and Photodynamic Therapy 2004;1:279-93.

[6] Plaetzer K, Krammer B, Berlanda J, Berr F, Kiesslich T. Photophysics and photochemistry of photodynamic therapy: fundamental aspects. Lasers in Medical Science 2009;24:259-68.

[7] Huang Z, Xu H, Meyers AD, et al. Photodynamic therapy for treatment of solid tumors - potential and technical challenges. Technology in Cancer Research and Treatment 2008;7:309-20.

[8] O'Connor AE, Gallagher WM, Byrne AT. Porphyrin and nonporphyrin photosensitizers in oncology: preclinical and clinical advances in photodynamic therapy. Photochemistry and Photobiology 2009;85:1053-74.

[9] Triesscheijn M, Baas P, Schellens JH, Stewart FA. Photodynamic therapy in oncology. The Oncologist 2006;11:1034-44.

[10] Senge MO, Brandt JC. Temoporfin (Foscan $^{\circledR}, 5,10,15,20$ tetra(m-hydroxyphenyl)chlorin)-a second-generation photosensitizer. Photochemistry and Photobiology 2011;87:1240-96.

[11] Songca SP. In vitro activity and tissue distribution of new fluorinated meso-tetrahydroxyphenylporphyrin photosensitizers. Journal of Pharmacy and Pharmacology 2001;53:1469-75.

[12] Banfi S, Caruso E, Buccafurni L, et al. Comparison between 5,10,15,20-tetraaryl- and 5,15-diarylporphyrins as photosensitizers: synthesis, photodynamic activity, and quantitative structure-activity relationship modeling. Journal of Medicinal Chemistry 2006;49:3293-304. 
[13] Serra A, Piñeiro $M$, Santos $\mathrm{Cl}$, et al. In vitro photodynamic activity of 5,15-bis(3-hydroxyphenyl)porphyrin and its halogenated derivatives against cancer cells. Photochemistry and Photobiology 2010;86:206-12.

[14] Gariboldi MB, Ravizza R, Baranyai P, et al. Photodynamic effects of novel 5,15-diaryl-tetrapyrrole derivatives on human colon carcinoma cells. Bioorganic and Medicinal Chemistry 2009;17:2009-16.

[15] Serra AC, Piñeiro $M$, Rocha-Gonsalves, et al. Halogen atom effect on photophysical and photodynamic characteristics of derivatives of 5,10,15,20-tetrakis(3-hydroxyphenyl)porphyrin. Journal of Photochemistry and Photobiology B 2008;92: $59-65$.

[16] Mosmann T. Rapid colorimetric assay for cellular growth and survival: application to proliferation and cytotoxicity assays. Journal of Immunological Methods 1983;65:55-63.

[17] Aubry JP, Blaecke A, Lecoanet-Henchoz S, et al. Annexin V used for measuring apoptosis in the early events of cellular cytotoxicity. Cytometry 1999;37:197-204.

[18] Abrantes AM, Serra ME, Gonçalves AC, et al. Hypoxia-induced redox alterations and their correlation with $99 \mathrm{mTC}-\mathrm{MIBI}$ and 99mTc-HL-91 uptake in colon cancer cells. Nuclear Medicine and Biology 2010;37:125-32.

[19] Ling $\mathrm{H}$, Fu LI, lao YX, et al. Involvement of mitochondrial pathway in triptolide-induced cytotoxicity in human normal liver L-02 cells. Biological and Pharmaceutical Bulletin 2008;31:592-7.

[20] Tarpey MM, Wink DA, Grisham MB. Methods for detection of reactive metabolites of oxygen and nitrogen: in vitro and in vivo considerations. American Journal of Physiology 2004;286:431-44.

[21] Dikalov S, Griendling KK, Harrison DG. Measurement of reactive oxygen species in cardiovascular studies. Hypertension 2007; 49:717-27.

[22] Zhao H, Joseph J, Fales HM, et al. Detection and characterization of the product of hydroethidine and intracellular superoxide by HPLC and limitations of fluorescence. Proceedings of the National Academy of Sciences of the United States of America 2005;102:5727-32.

[23] Dagrosa $M$, Viaggi $M$, Longhino J, et al. Experimental application of boron neutron capture therapy to undifferentiated thyroid carcinoma. International Journal of Radiation Oncology 2003;57:1084-92.

[24] Yoon CJ, Chung JW, Park JH, et al. Transcatheter arterial embolization with 188Rhenium-HDD-labeled iodized oil in rabbit VX2 liver tumor. Journal of Vascular and Interventional Radiology 2004;15:1121-8.

[25] Abrantes AM, Rio Serra ME, Gonçalves C, et al. Tumour hypoxia and technetium tracers: in vivo studies. Current Radiopharmaceuticals 2012;5:99-105.

[26] Bourré L, Thibaut S, Fimiani M, Ferrand Y, Simonneaux G, Patrice T. In vivo photosensitizing efficiency of a diphenylchlorin sensitizer: interest of a DMPC liposome formulation. Pharmacological Research 2003;47:253-61.

[27] Ferrand Y, Bourré L, Simonneaux G. Hydroporphyrins as tumour photosensitizers: synthesis and photophysical studies of 2,3-dihydro-5,15-di(3,5-dihydroxyphenyl) porphyrin. Bioorganic and Medicinal Chemistry Letters 2003;13:833-5.

[28] Berenbaum MC, Akande SL, Bonnett R, et al. Mesotetra(hydroxyphenyl)porphyrins, a new class of potent tumour photosensitisers with favourable selectivity. British Journal of Cancer 1986;54:717-25.

[29] Azenha EG, Serra AC, Pineiro M, et al. Heavy-atom effects on metalloporphyrins and polyhalogenated porphyrins. Chemical Physics 2002;280:177-90.

[30] Piñeiro $M$, Carvalho AL, Pereira $M M$, Rocha-Gonsalves $A M$, Arnaut LG, Formosinho SJ. Photoacoustic measurements of porphyrin triplet-state quantum yields and singlet-oxygen efficiencies. Chemistry - A European Journal 1998;4: 2299-307.

[31] Leung WN, Sun X, Mak NK, Yow CM. Photodynamic effects of mTHPC on human colon adenocarcinoma cells: photocytotoxicity, subcellular localization and apoptosis. Photochemistry and Photobiology 2002;75:406-11.

[32] Marchal S, Bezdetnaya L, Guillemin F. Modality of cell death induced by Foscan-based photodynamic treatment in human colon adenocarcinoma cell line HT29. Biochemistry 2004;69:45-9.

[33] Robertson CA, Evans DH, Abrahamse H. Photodynamic therapy (PDT): a short review on cellular mechanisms and cancer research applications for PDT. Journal of Photochemistry and Photobiology B 2009;96:1-8.

[34] Uzdensky AB, Ma LM, lani V, Hjortland GO, Steen HB, Moan $\mathrm{J}$. Intracellular localisation of hypericin in human glioblastoma and carcinoma cell lines. Lasers in Medical Science 2001;16:276-83.

[35] Kolarova H, Lenobel R, Kolar P, Strnad M. Sensitivity of different cell lines to phototoxic effect of disulfonated chloroaluminium phthalocyanine. Toxicology in Vitro 2007;21:1304-6.

[36] Kolarova H, Nevrelova P, Bajgar R, Jirova D, Kejlova K, Strnad $M$. In vitro photodynamic therapy on melanoma cell lines with phthalocyanine. Toxicology in Vitro 2007;21:249-53.

[37] Picard N, Ali H, van Lier JE, Klarskov K, Paquette B. Bromines on $\mathrm{N}$-allyl position of cationic porphyrins affect both radio- and photosensitizing properties. Photochemical \& Photobiological Sciences 2009;8:224-32.

[38] Gryshuk AL, Chen Y, Potter W, Ohulchansky T, Oseroff A, Pandey RK. In vivo stability and photodynamic efficacy of fluorinated bacteriopurpurinimides derived from bacteriochlorophyll-a. Journal of Medicinal Chemistry 2006;49:1874-81.

[39] Osterloh J, Vicente MGH. Mechanisms of porphyrinoid localization in tumors. Journal of Porphyrins and Phthalocyanines 2002;6:305-24.

[40] Marchal S, Fadloun A, Maugain E, D'Hallewin ME, Guillemin F, Bezdetnaya L. Necrotic and apoptotic features of cell death in response to Foscan photosensitization of HT29 monolayer and multicell spheroids. Biochemical Pharmacology 2005;69:1167-76.

[41] Banfi S, Caruso E, Caprioli S, et al. Photodynamic effects of porphyrin and chlorin photosensitizers in human colon adenocarcinoma cells. Bioorganic \& Medicinal Chemistry 2004;12:4853-60.

[42] Dougherty TJ, Gomer CJ, Henderson BW, et al. Photodynamic therapy. Journal of the National Cancer Institute 1998;90:889-905.

[43] Leist M, Nicotera P. The shape of cell death. Biochemical and Biophysical Research Communications 1997;236:1-9.

[44] Mikes J, Kleban J, Sacková V, et al. Necrosis predominates in the cell death of human colon adenocarcinoma HT-29 cells treated under variable conditions of photodynamic therapy with hypericin. Photochemical \& Photobiological Sciences 2007;6:758-66.

[45] Robertson CA, Tech $M$, Abrahamse $H$. The in vitro PDT efficacy of a novel metallophthalocyanine (MPC) derivative and established 5-ALA photosensitizing dyes against human metastatic melanoma cells. Lasers in Surgery and Medicine 2011;24:766-76.

[46] Rodrigues NR, Rowan A, Smith ME, et al. p53 mutations in colorectal cancer. Proceedings of the National Academy of Sciences of the United States of America 1990;87:7555-9.

[47] Castano A, Demidova T, Hamblin M. Mechanisms in photodynamic therapy: part two-cellular signaling, cell metabolism and modes of cell death. Photodiagnosis and Photodynamic Therapy 2005;2:1-23.

[48] Castano AP, Mroz P, Hamblin MR. Photodynamic therapy and anti-tumour immunity. Nature Reviews Cancer 2006;6:535-45. 
[49] Peng Q, Warloe T, Moan J, et al. Antitumor effect of 5aminolevulinic acid-mediated photodynamic therapy can be enhanced by the use of a low dose of photofrin in human tumor xenografts. Cancer Research 2001;61:5824-32.

[50] Stott B, Korbelik M. Activation of complement C3, C5, and C9 genes in tumors treated by photodynamic therapy. Cancer Immunology, Immunotherapy 2007;56:649-58.

[51] Schaffer M, Schaffer PM, Corti L, et al. Photofrin as a specific radiosensitizing agent for tumors: studies in comparison to other porphyrins, in an experimental in vivo model. Journal of Photochemistry and Photobiology B 2002;66:157-64.

[52] Lim Y, Yoo J, Park D, et al. Antitumor effect of photodynamic therapy with chlorin-based photosensitizer DH-II-24 in colorectal carcinoma. Cancer Science 2009;100:2431-6.

[53] Hajri A, Wack S, Meyer C, et al. In vitro and in vivo efficacy of photofrin and pheophorbide a, a bacteriochlorin, in photodynamic therapy of colonic cancer cells. Photochemistry and Photobiology 2002;75:140-8. 